wheeze, or breathlessness?'). ${ }^{3}$

In the UK, there are a total of over 800000 (prevalence 1.5\%) people on general practice COPD registers (Quality and Outcomes Framework data). ${ }^{4}$ However, cross-sectional studies and extrapolation of data indicate that the actual prevalence should be nearer to $4 \%$. More than half of the people with COPD are currently not identified. ${ }^{5,6}$ The main conclusion is that symptoms are unreliable and the availability of spirometry for all those at risk remains the only way to identify those missing millions.

Until NICE comes fully into line within criteria for diagnosis and is prepared to ignore unreliable subjective symptom scoring, then these figures are unlikely to improve and a state of confusion and uncertainty will remain.

\section{Gary Parkes,}

GP/Researcher, The Limes Surgery,

Hoddesdon, Herts.

E-mail:parkesko@hotmail.co.uk

\section{REFERENCES}

1. O’Reilly J, Jones MM, Parnham J, et al. Management of stable chronic obstructive pulmonary disease in primary and secondary care: summary of updated NICE guidance. $B M J$ 2010; 340: c3134.

2. Agusti A, Calverley PM, Celli B, et al. Characterisation of COPD heterogeneity in the ECLIPSE cohort. Respir Res 2010; 11: 122.

3. Lu M, Yao WZ, Zhong NS, et al. Asymptomatic patients of chronic obstructive pulmonary disease in China. Chin Med J (Engl) 2010; 123(12): 1494-1499.

4. NHS. Quality and Outcomes Framework (QOF) for April 2008 - March 2009, England numbers on QOF disease registers and raw prevalence rates, England. http://www.ic.nhs.uk/ (accessed 15 Feb 2011).

5. Van Schayck CP, Loozen JMC, Wagena E, et al. Detecting patients at a high risk of developing chronic obstructive pulmonary disease in general practice: cross sectional case finding study. BMJ 2002; 324(7350): 1370.

6. Shahab L, Jarvis MJ, Britton J, West R. Prevalence, diagnosis and relation to tobacco dependence of chronic obstructive pulmonary disease in a nationally representative population sample. Thorax 2006; 61(12): 1043-1047.

\section{Screening for atrial fibrillation}

I was reading with interest the article of Lewis et al about the use of a new gadget for the detection of atrial fibrillation in general practice. ${ }^{1}$ The diagnosis of atrial fibrillation is very important, but do we need to invest in further instruments to screen for atrial fibrillation?

I think a cardiac auscultation should be part of a consultation, especially in the high older risk group. I diagnosed people in their 50 s with atrial fibrillation who consulted me for their phimosis or for losing weight. Initially amused about the cardiac auscultation they were very thankful when I explained that their heart rhythm, if not treated, could cause serious problems in the future, for example, stroke.

Despite having had several consultations as a patient with several GPs in my life, no one checked my blood pressure or did auscultate my heart as yet (despite me being in my 50s). We have to come back to the physical examination that is more costeffective and a quick screening tool when it is combined with prior adequate training and clinical reasoning. Not only are rhythm disturbances important, but structural heart disease can be asymptomatic, for example, in aortic regurgitation, despite being a serious cardiac abnormality.

Normal physical examination can exclude valvular regurgitation in asymptomatic patients, and no echocardiogram is necessary. If GP colleagues feel rusty regarding cardiac auscultation there are very good websites available to update oneself with murmurs and rhythms, or one could sit in with a cardiology colleague. One good heart sound tutorial, that is available free on the internet is 'Blaufuss Multimedia - Heart Sounds and Cardiac Arrhythmias'.2

I hope that we are all listening to the patient more. This is not meant only for the soul, but applies to the body as well.

\section{Bernard Klemenz,}

Northern Road Surgery, 56 Northern Road, Cosham, P06 3DS.

E-mail: bernard@doctors.org.uk

\section{REFERENCES}

1. Lewis M, Parker D, Weston C, Bowes M. Screening for atrial fibrillation; sensitivity and specificity of a new methodology. Br J Gen Pract 2011; 61(582): 38-39.

2. Blaufuss A. Cardiac examinations/heart sounds. http://www.blaufuss.org/ (accessed 7 Mar 2011).

DOI: 10.3399/bjgp11X567243

\section{Integrated medicine}

Brien et al interviewed 35 patients who were using complementary and alternative medicine (CAM) in parallel with orthodox medicine. ${ }^{1}$ They state that 'there has been no direct research into how individuals use CAM and OM (orthodox medicine) in relation to each other ...'. This may not be entirely correct. In 1997 , we published a survey of 3384 arthritis sufferers and analysed the data of 496 patients using both orthodox medicine and CAM. ${ }^{2}$ Our results suggested that orthodox medicine was generally perceived as more effective but the therapeutic encounters with providers of CAM were perceived as more satisfying. For instance, $64 \%$ of patients felt that CAM clinicians spent enough time with them, while, for orthodox doctors, the figure was only $45 \%$. Brien at al ${ }^{1}$ show that, predictably, patients use CAM and orthodox medicine in 'different ways'. I suggest that our 1997 findings $^{2}$ go some way in explaining why.

\section{Edzard Ernst,}

Peninsula Medical School, Exeter.

E-mail: eernst@pms.ac.uk

\section{REFERENCES}

1. Brien SB, Bishop FL, Riggs K, et al. Integrated medicine in the management of chronic illness: a qualitative study. Br J Gen Pract 2010; DOI: 10.3399/bjgp11X556254

2. Resch KL, Hill S, Ernst E. Use of complementary therapies by individuals with 'arthritis'. Clin Rheumatol 1997; 16(4): 391-395.

\title{
Medical migrants
}

The article by Simpson and Esmail in the 